\title{
Clinical Features and Survival of Young Adults with Stage IV Gastric Cancer: A Japanese Population- based Study
}

Ryuya Yamamoto ( $\sim$ dragon1119scorpion@gmail.com )

Southern Tohoku General Hospital https://orcid.org/0000-0001-5957-7494

Michitaka Honda

Fukushima Medical University

Hidetaka Kawamura

Fukushima Medical University

Hiroshi Kobayashi

Fukushima Medical University

Koichi Takiguchi

The Takeda Healthcare Foundation Takeda General Hospital

Atsushi Muto

Fukushima Rosai Hospital: Fukushima Rosai Byoin

Shigeru Yamazaki

Ohta Nishinouchi Hospital: Ota Nishinouchi Byoin

Yasushi Teranishi

Southern Tohoku General Hospital

Satoru Shiraso

Iwaki City Medical Center

Koji Kono

Fukushima Medical University

Soshi Hori

Fukushima Medical University

Takahiro Kamiga

Shirakawa Kousei General Hospital: Shirakawa Kosei Sogo Byoin

Toshiyasu Iwao

Aizu Chuo Hospital

Naoyuki Yamashita

Tsuboi Hospital 
Keywords: young adult, age of onset, gastric cancer, stomach neoplasms

Posted Date: June 4th, 2021

DOI: https://doi.org/10.21203/rs.3.rs-573767/v1

License: (c) (1) This work is licensed under a Creative Commons Attribution 4.0 International License. Read Full License

Version of Record: A version of this preprint was published at Journal of Gastrointestinal Cancer on January 7th, 2022. See the published version at https://doi.org/10.1007/s12029-021-00797-6. 


\section{Abstract}

Purpose: With the aging of society, the age of patients with gastric cancer (GC) in Japan has been increasing. However, there are few documented outcomes for young patients with stage IV GC. We investigated the clinical characteristics and prognosis of patients with stage IV GC aged under 40 years using a dataset from an integrated population-based cohort study.

Methods: We conducted this multicenter population-based cohort study to determine whether earlier onset of GC was a poor prognostic factor. We enrolled patients with metastatic GC aged under 40 years (young group) and those aged between 60 and 75 years (middle-aged group). Patients were histologically diagnosed as having gastric adenocarcinoma. We evaluated the overall survival (OS) of both groups and the hazard ratio (HR) for OS based on age. The adjusted HR with 95\% confidence interval (Cl) was evaluated using the Cox proportional hazards model after adjusting for confounding factors, including sex, histology, number of metastatic lesions, surgical resection, and chemotherapy.

Results: This study enrolled 555 patients. The patients were classified into the young group $(n=20)$ and the middle-aged group $(n=535)$. The median OS values were 5.7 months and 8.8 months in the young and middle-aged groups, respectively $(P=0.029)$. The adjusted $\mathrm{HR}(95 \% \mathrm{Cl})$ of the young group was 1.88 $(1.17-3.04, P=0.009)$.

Conclusions: Age was an independent prognostic factor in patients with stage IV GC. Further studies investigating the genomic characteristics of GC and exploring more effective chemotherapeutic agents are required.

\section{Introduction}

The mean age of patients at onset of gastric cancer (GC) ranges from 60 to 70 years [1-3]. This mean age has gradually increased in Japan [4], possibly because of the drastic decline in the prevalence of Helicobacter pylori infection among the younger generation. H. pylori infection significantly affects GC development $[5,6])$. However, approximately $2-10 \%$ of patients with $\mathrm{GC}$ are aged 40 years or under [7].

Previous reports have demonstrated that the prognosis of young patients with resectable stage I- III GC is similar to or better than that of middle-aged or older patients [3,8-10]. Younger patients have fewer comorbidities and a higher tolerance for surgery and adjuvant chemotherapy than older patients $[11,12]$. Additionally, they can undergo intensive chemotherapy followed by gastrectomy with adequate lymph node dissection, which improves long-term prognosis $[13,14]$. However, some young patients present with rapidly progressive disease and distant metastasis. These patients are diagnosed with stage IV GC at the initial presentation. Pathological differences have been observed between younger patients with GC and older patients with atrophic gastritis caused by H. pylori infection [15]. Previous reports have shown that poorly differentiated adenocarcinoma, diffuse invasive type, and lymphatic or distant metastasis are more common in younger patients than in older patients $[2,3,16]$. A treatment strategy for stage IV disease in younger patients should be established. However, most previous studies have focused on the 
surgical outcomes of young patients with resectable GC. These studies were limited because data were obtained from a single institute, and there are few documented outcomes of young patients with stage IV GC.

We investigated the clinical characteristics and prognosis of young patients with stage IV GC using a dataset from an integrated population-based cohort study. We hypothesized that the survival time of young patients was worse than that of middle-aged patients.

\section{Patients And Methods}

\section{Study design and cohort development}

This was a population-based study. All nine hospitals designated for cancer treatment in the Fukushima Prefecture participated in this study. First, patients with stage IV GC were enlisted using hospital-based cancer registries. Subsequently, individual patient data, including age, sex, body mass index, performance status, Charlson comorbidity index [17], discovery of symptoms, site, morphological type, histological type, metastatic sites, number of metastatic lesions, operation type, and chemotherapy, were obtained. We merged the datasets from each participating institute after anonymizing the information.

We enrolled patients in this study if they were diagnosed with GC (International Classification of Diseases, Tenth Revision, C16.0-16.9) and had histologically proven adenocarcinoma (differentiated type, undifferentiated type, and mixed type) from a primary lesion between 2008 and 2015. Patients who were lost to follow-up, had multiple primary cancers, or did not undergo biopsy were excluded.

The protocol, registered at the University Hospital Medical Information Network (UMIN000033718), was approved by the institutional review board of all participating hospitals. This board waived the informed consent requirement in accordance with the Japanese government's Ethical Guidelines for Medical and Health Research Involving Human Subjects, which allow an opt-out approach.

\section{Definition of gastric cancer patient groups}

Patients aged under 40 years were classified as "young" patients, whereas those aged 60-75 years were classified as "middle-aged" patients. The age when patients were diagnosed with GC was considered in the analysis. The methods of previous studies and the age distribution histogram between 2008 and 2015 were considered. Figure 1 shows the age distribution histogram of 1366 patients diagnosed with stage IV GC in this period.

\section{Outcomes and statistical analyses}

The primary outcome was the young group's hazard ratio (HR) for overall survival (OS). After adjusting for sex, histological type, number of metastatic lesions, primary lesion resection, and chemotherapy as confounding factors, we calculated the HR and $95 \%$ confidence interval $(\mathrm{Cl})$ of both groups using the Cox proportional hazards model. Kaplan-Meier curves were used to illustrate the cumulative incidence of 
deaths in the young and middle-aged groups, and a log-rank test was performed to compare the OS of these patient groups. Descriptive statistics were also evaluated. Continuous variables were compared using Student's $t$ test, and categorical variables were compared using Fisher's exact test. All statistical tests were two sided, and $P$ values $\leq 0.05$ were considered statistically significant. All statistical analyses were performed using R software version 4.0.3 (https://www.R-project.org/; Lucent Technologies, Vienna, Austria).

\section{Results}

\section{Enrolled patients}

Figure 2 presents the patient enrollment flowchart. A total of 555 patients were enrolled in this study. Twenty patients were included in the young group, and 535 patients were included in the middle-aged group. Table 1 shows patient characteristics, and Table 2 shows treatment details in the two groups. Histological types were more differentiated in the middle-aged group and poorly differentiated in the young group $(P=0.003)$. The young group had a lower transition rate to third-line chemotherapy than the middle-aged group $(P=0.11)$. 
Table 1

Patient characteristics

\begin{tabular}{|c|c|c|c|c|c|}
\hline \multicolumn{2}{|l|}{ Variable } & \multirow{2}{*}{$\begin{array}{l}\text { Young }(n= \\
20)\end{array}$} & \multirow[t]{2}{*}{ (\%) } & \multirow{2}{*}{$\begin{array}{l}\text { Middle-aged (n } \\
=535) \\
68(60-75)\end{array}$} & \multirow[t]{2}{*}{ (\%) } \\
\hline Age (years) & Median (range) & & & & \\
\hline \multirow[t]{2}{*}{ Sex } & Male & 13 & 65 & 411 & 76.8 \\
\hline & Female & 7 & 35 & 124 & 23.2 \\
\hline BMI $\left(\mathrm{kg} / \mathrm{m}^{2}\right)$ & Mean (range) & $\begin{array}{l}20.2(13.0- \\
25.9)\end{array}$ & & $\begin{array}{l}19.7(10.5- \\
21.3)\end{array}$ & \\
\hline \multirow{2}{*}{$\begin{array}{l}\text { Charlson comorbidity } \\
\text { index }\end{array}$} & $0-2$ & 20 & 100 & 497 & 92.9 \\
\hline & $>3$ & 0 & 0 & 38 & 7.1 \\
\hline \multirow{3}{*}{$\begin{array}{l}\text { Discovered based on } \\
\text { symptoms }\end{array}$} & Yes & 16 & 80 & 251 & 46.9 \\
\hline & No & 4 & 20 & 284 & 53.1 \\
\hline & $\begin{array}{l}\text { Detected by cancer } \\
\text { screening }\end{array}$ & 0 & 0 & 40 & 7.5 \\
\hline \multirow[t]{4}{*}{ Site } & Upper & 6 & 30 & 134 & 25 \\
\hline & Middle & 13 & 65 & 171 & 32 \\
\hline & Lower & 1 & 5 & 171 & 32 \\
\hline & Entire & 0 & - & 54 & 10.1 \\
\hline \multirow[t]{2}{*}{ Morphological type } & Type 4 & 10 & 50 & 94 & 17.6 \\
\hline & Others & 10 & 50 & 425 & 79.4 \\
\hline \multirow[t]{3}{*}{ Histological type } & Tub, pap & 0 & - & 186 & 34.8 \\
\hline & Por, sig, muc & 17 & 85 & 296 & 55.3 \\
\hline & Mix & 3 & 15 & 53 & 9.9 \\
\hline \multirow[t]{3}{*}{ Metastatic site ${ }^{a}$} & $\begin{array}{l}\text { Peritoneal } \\
\text { dissemination }\end{array}$ & 15 & 75 & 279 & 52.1 \\
\hline & Liver & 4 & 20 & 206 & 38.5 \\
\hline & Lymph node & 7 & 35 & 245 & 45.8 \\
\hline \multicolumn{6}{|c|}{ a Some patients had metastasis at more than one site. } \\
\hline $\begin{array}{l}\text { BMI, body mass index; } \\
\text { differentiated adenoca } \\
\text { mixed type. }\end{array}$ & $\begin{array}{l}\text { ubular adenocarcino } \\
\text { ma; sig, signet-ring c }\end{array}$ & $\begin{array}{l}\text { ap, papillary } \\
\text { cinoma; muc }\end{array}$ & $\begin{array}{l}\text { enoca } \\
\text { ucinc }\end{array}$ & $\begin{array}{l}\text { inoma; por, poorl } \\
\text { s adenocarcinom }\end{array}$ & $\operatorname{mix}$ \\
\hline
\end{tabular}




\begin{tabular}{|c|c|c|c|c|c|}
\hline \multicolumn{2}{|l|}{ Variable } & \multirow{2}{*}{$\begin{array}{l}\text { Young }(n= \\
20) \\
1\end{array}$} & \multirow{2}{*}{$\begin{array}{l}(\%) \\
5\end{array}$} & \multirow{2}{*}{$\begin{array}{l}\text { Middle-aged (n } \\
=535) \\
36\end{array}$} & \multirow{2}{*}{$\begin{array}{l}\text { (\%) } \\
6.7\end{array}$} \\
\hline & Lung & & & & \\
\hline & Bone & 2 & 10 & 21 & 3.9 \\
\hline & Others & 3 & 15 & 41 & 7.7 \\
\hline \multirow{3}{*}{$\begin{array}{l}\text { Number of metastatic } \\
\text { lesions }\end{array}$} & One & 12 & 60 & 302 & 56.4 \\
\hline & Two & 4 & 20 & 152 & 28.4 \\
\hline & Three or more & 4 & 20 & 69 & 12.9 \\
\hline \multicolumn{6}{|c|}{ a Some patients had metastasis at more than one site. } \\
\hline \multicolumn{6}{|c|}{$\begin{array}{l}\text { BMI, body mass index; tub, tubular adenocarcinoma; pap, papillary adenocarcinoma; por, poorly } \\
\text { differentiated adenocarcinoma; sig, signet-ring cell carcinoma; muc, mucinous adenocarcinoma; mix, } \\
\text { mixed type. }\end{array}$} \\
\hline
\end{tabular}

Table 2

Treatment details

\begin{tabular}{|c|c|c|c|c|c|}
\hline Variable & & Young $(n=20)$ & (\%) & Middle-aged $(n=535)$ & (\%) \\
\hline \multirow[t]{2}{*}{ Operation } & TG & 5 & 25 & 111 & 20.7 \\
\hline & DG & 2 & 10 & 66 & 12.3 \\
\hline \multirow{2}{*}{$\begin{array}{l}\text { Resection } \\
\text { margins }\end{array}$} & RO & 1 & 5 & 27 & 5 \\
\hline & $\mathrm{R} 1,2$ & 5 & 25 & 137 & 25.6 \\
\hline \multirow[t]{5}{*}{ Chemotherapy } & $\begin{array}{l}\text { First-line } \\
\text { monotherapy }\end{array}$ & 3 & 15 & 105 & 19.6 \\
\hline & $\begin{array}{l}\text { First-line } \\
\text { combination therapy }\end{array}$ & 14 & 70 & 310 & 57.9 \\
\hline & First-line & 17 & 85 & 415 & 77.6 \\
\hline & Second-line & 9 & 45 & 216 & 40.4 \\
\hline & Third-line & 1 & 5.0 & 112 & 20.9 \\
\hline
\end{tabular}

\section{Adjusted hazard ratios and overall survival curves}

Table 3 shows the adjusted HRs for all patients. With the HR of the middle-aged group as a reference, the $\mathrm{HR}(95 \% \mathrm{Cl})$ of the young group was $1.88(1.17-3.04, P=0.009)$. Figure 3 shows the OS and at-risk 
population for both groups. The median OS values were 5.7 months and 8.8 months in the young and middle-aged groups, respectively $(P=0.029)$.

Table 3

Hazard ratios of potential prognostic factors

\begin{tabular}{|c|c|c|c|c|}
\hline Variable & Reference & Hazard ratio & $95 \% \mathrm{Cl}$ & $P$ value \\
\hline Young & Middle-aged & 1.88 & $1.17-3.04$ & 0.009 \\
\hline Female & Male & 0.97 & $0.79-1.20$ & 0.79 \\
\hline Por, sig, muc & Tub, pap, mix & 1.22 & $1.00-1.44$ & 0.054 \\
\hline Resection of primary lesion & No & 0.34 & $0.27-0.42$ & $<0.001$ \\
\hline Chemotherapy & No & 0.25 & $0.19-0.31$ & $<0.001$ \\
\hline Two or more metastatic lesions & One lesion & 1.18 & $0.98-1.44$ & 0.087 \\
\hline
\end{tabular}

\section{Discussion}

This study yielded four important results. First, age under 40 years was identified as an independent risk factor for survival. Second, the predominant histological type in the young group was poorly differentiated, and the typical metastatic pattern was peritoneal dissemination. Third, the proportion of patients who received third-line chemotherapy was lower in the young group than in the middle-aged group. Finally, we suggest that the survival of younger patients is worse than that of middle-aged patients.

Previous studies have reported that the prognosis of patients aged under 40 years with stage I-III GC is comparable to or better than that of patients aged $\geq 40$ years $[4,8-10,18]$. We focused on patients with stage IV GC in this study and found that the young group had a worse prognosis than the middle-aged group. Young patients were more likely to have undifferentiated type GC, resulting in a higher incidence of peritoneal dissemination than hematogenous metastasis. Peritoneal dissemination can present with a more rapid progression than liver or lymph node metastasis, and the switch to chemotherapy is often unsuccessful. In the present study, the rate of third-line treatment in young patients was lower than that in middle-aged patients, reflecting the difficulty of treating peritoneal dissemination.

The prevalence of $H$. pylori infection among young Japanese people is low. Therefore, GC development in people aged under 40 years may involve carcinogenesis pathways and biological properties that are different from those of common GC secondary to atrophic gastritis. The molecular mechanisms of gastric carcinogenesis have recently been elucidated, and potential therapeutic targets have been identified based on the classification of molecular subtypes [19]. The genomically stable GC subtype is 
more common in younger patients, has the highest resistance to fluorouracil, and is associated with poor prognosis [20]. In addition, the chromosomal instability GC subtype, which is associated with extensive gastric mucosal atrophy owing to $H$. pylori infection, is more sensitive to chemotherapy and has less recurrence after adjuvant therapy than other subtypes [20]. These molecular differences may be related to differences in chemotherapy efficacy and GC progression. Young patients with stage IV GC who already have distant metastasis at the time of diagnosis require shorter intervals between examinations and earlier evaluation of treatment effects.

Previous studies have shown that younger age was not a poor prognostic factor for stage I-III GC [18,21]. However, for stage IV GC, younger age indicated poorer prognosis in our study. Early-onset disease includes rare cases of rapid progression. Patient survival is short when the disease is detected at stage IV.

This study has a few limitations. First, information on $\mathrm{H}$. pylori infection and genetic information ( $\mathrm{CDH} 1$ mutation, RhoA, microsatellite instability, and loss of heterozygosity) were not collected. Second, the number of cases in the young group was small, which could interfere with the reliability of our results. However, young patients with GC are rare, and stage IV GC cases are uncommon $[9,16]$. In our study, young patients with stage IV GC accounted for approximately $1.5 \%$ of the entire cohort. Therefore, the results of this study are meaningful and distinct since they focused on early-onset stage IV GC.

In conclusion, younger age (under 40 years) was an independent prognostic factor for patients with stage IV GC. Although this is a rather rare population among patients with stage IV GC, further studies investigating the genomic characteristics of GC and exploring more effective chemotherapeutic agents are required.

\section{Declarations}

\section{Funding}

This research received no specific grant from any funding agency in the public, commercial, or not-forprofit sectors.

\section{Conflict of interest}

The authors declare no conflicts of interest associated with this manuscript.

\section{Availability of data and material}

The data that support the findings of this study are available from the corresponding author, M.H., upon reasonable request. 


\section{Code availability}

The data that support the findings of this study are available from the corresponding author, M.H., upon reasonable request.

\section{Authors' contributions}

Category 1

Conception and design of the study: R.Y., M.H., H.K., and H.K.; acquisition of data: M.H., H.K., H.K., and S.H.; and analysis and/or interpretation of data: R.Y. and M.H.

Category 2

Drafting the manuscript: R.Y. and M.H. and revising the manuscript critically for important intellectual content: R.Y. and M.H.

Category 3

Approval of the version of the manuscript to be published: R.Y., M.H., H.K., H.K., K.T., A.M., S.Y., Y.T., S.S., K.K., S.H., T.K., T.I., and N.Y.

\section{Ethics approval}

All study procedures were performed in accordance with the ethical standards of the respective committees on human experimentation (institutional and national) and with the Declaration of Helsinki of 1964 and later versions. The study was approved by the institutional review board of all participating institutes.

\section{Consent to participate}

The anonymous nature of the data allowed the requirement for informed consent to be waived.

\section{Consent for publication}

All authors provided consent for the publication of this study.

\section{References}

1. Charles PT, Christian DV, Greg K et al (1996) Gastric adenocarcinoma in patients 40 years of age or younger. Am J Surg 172:473-47 https://doi.org/10.1016/s0002-9610(96)00223-1 
2. Peng S, Lei W, Bo J, Liu Z, Cao K, Guan W (2016) Age-specific effects on the prognosis after surgery for gastric cancer: a SEER population-based analysis. Oncotarget 7:48614-486 https://dx.doi.org/10.18632\%2Foncotarget.9548

3. Takatsu Y, Hiki N, Nunobe $S$ et al (2016) Clinicopathological features of gastric cancer in young patients. Gastric Cancer19:472-47 http://dx.doi.org/10.1007/s10120-015-0484-1

4. Honda M, Wong SL, Healy MA et al (2017) Long-term trends in primary sites of gastric adenocarcinoma in Japan and the United States. J Cancer 8:1935-19 http://dx.doi.org/10.7150/jca.19174

5. Shiota S, Murakawi K, Suzuki R, Fujioka T, Yamaoka Y (2013) Helicobacter pylori infection in Japan. Expert Rev Gastroenterol Hepatol 7:35-40. http://dx.doi.org/10.1586/egh.12.67

6. Balakrishnan M, George R, Sharma A, Graham DY (2017) Changing trends in stomach cancer throughout the world. Curr Gastroenterol Rep 19:36. http://dx.doi.org/10.1007/s11894-017-0575-8

7. Ławniczak M, Gawin A, Jaroszewicz-Heigelmann H et al (2020) Analysis of clinicopathologic characteristics of gastric cancer in patients $\leq 40$ and $\geq 40$ years of age. Scand J Gastroenterol 55:62-66. https://doi.org/10.1080/00365521.2019.1699597

8. Santoro R, Carboni F, Lepiane P, Ettorre GM, Santoro E (2007) Clinicopathological features and prognosis of gastric cancer in young European adults. Br J Surg 94:737-742. http://dx.doi.org/10.1002/bjs.5600

9. Wang Z, Xu J, Shi Z et al (2016) Clinicopathologic characteristics and prognostic of gastric cancer in young patients. Scand J Gastroenterol 51:1043-1049.

http://dx.doi.org/10.1080/00365521.2016.1180707

10. Zhang J, Gan L, Xu M et al (2018) The prognostic value of age in non-metastatic gastric cancer after gastrectomy: a retrospective study in the U.S. and China. J Cancer 9:1188-1199. http://dx.doi.org/10.7150/jca.26949

11. Songun I, Putter H, Kranenbarg E, Sasako M, van de Velde CJH (2010) Surgical treatment of gastric cancer: 15-year follow-up results of the randomised nationwide Dutch D1D2 trial. Lancet Oncol 11:439-449. http://dx.doi.org/10.1016/S1470-2045(10)70070-X

12. Hsieh F, Wang Y, Hsu J, Liu KH, Yeh CN (2012) Clinicopathological features and prognostic factors of gastric cancer patients aged 40 years or younger. J Surg Oncol 105:304-309. http://dx.doi.org/10.1002/jso.22084

13. Ramos M, Pereira M, Sagae V et al (2019) Gastric cancer in young adults: a worse prognosis group? Rev Col Bras Cir 46:e20192256. http://dx.doi.org/10.1590/0100-6991e-20192256

14. Lee JG, Kim SA, Eun CS et al (2019) Impact of age on stage-specific mortality in patients with gastric cancer: a long-term prospective cohort study. PLoS One 14:e0220660. https://doi.org/10.1371/journal.pone.0220660

15. Li J (2020) Gastric cancer in young adults: a different clinical entity from carcinogenesis to prognosis. Gastroenterol Res Pract 2020:9512707. https://doi.org/10.1155/2020/9512707 
16. Rona K, Schwameis K, Zehetner J et al (2017) Gastric cancer in the young: an advanced disease with poor prognostic features. J Surg Oncol 115:371-375. http://dx.doi.org/10.1002/jso.24533

17. Charlson M, Szatrowski T, Peterson J, Gold J (1994) Validation of a combined comorbidity index. J Clin Epidemiol 47:1245-1251. http://dx.doi.org/10.1016/0895-4356(94)90129-5

18. Zhao B, Mei D, Wu Lv et al (2020) Clinicopathologic features, survival outcome, and prognostic factors in gastric cancer patients 18-40 years of age. J Adolesc Young Adult Oncol 9:514-521. http://dx.doi.org/10.1089/jayao.2019.0162

19. Cancer Genome Atlas Research Network (2014) Comprehensive molecular characterization of gastric adenocarcinoma. Nature 513:202-209. https://doi.org/10.1038/nature13480

20. Sohn B, Hwang J, Jang $H$ et al (2017) Clinical significance of four molecular subtypes of gastric cancer identified by The Cancer Genome Atlas project. Clin Cancer Res 23:4441-4449. http://dx.doi.org/10.1158/1078-0432.CCR-16-2211

21. Isobe T, Hashimoto K, Kizaki J et al (2013) Characteristic and prognosis of gastric cancer in young patients. Oncol Rep 30:43-49. http://dx.doi.org/10.3892/or.2013.2467

\section{Figures}




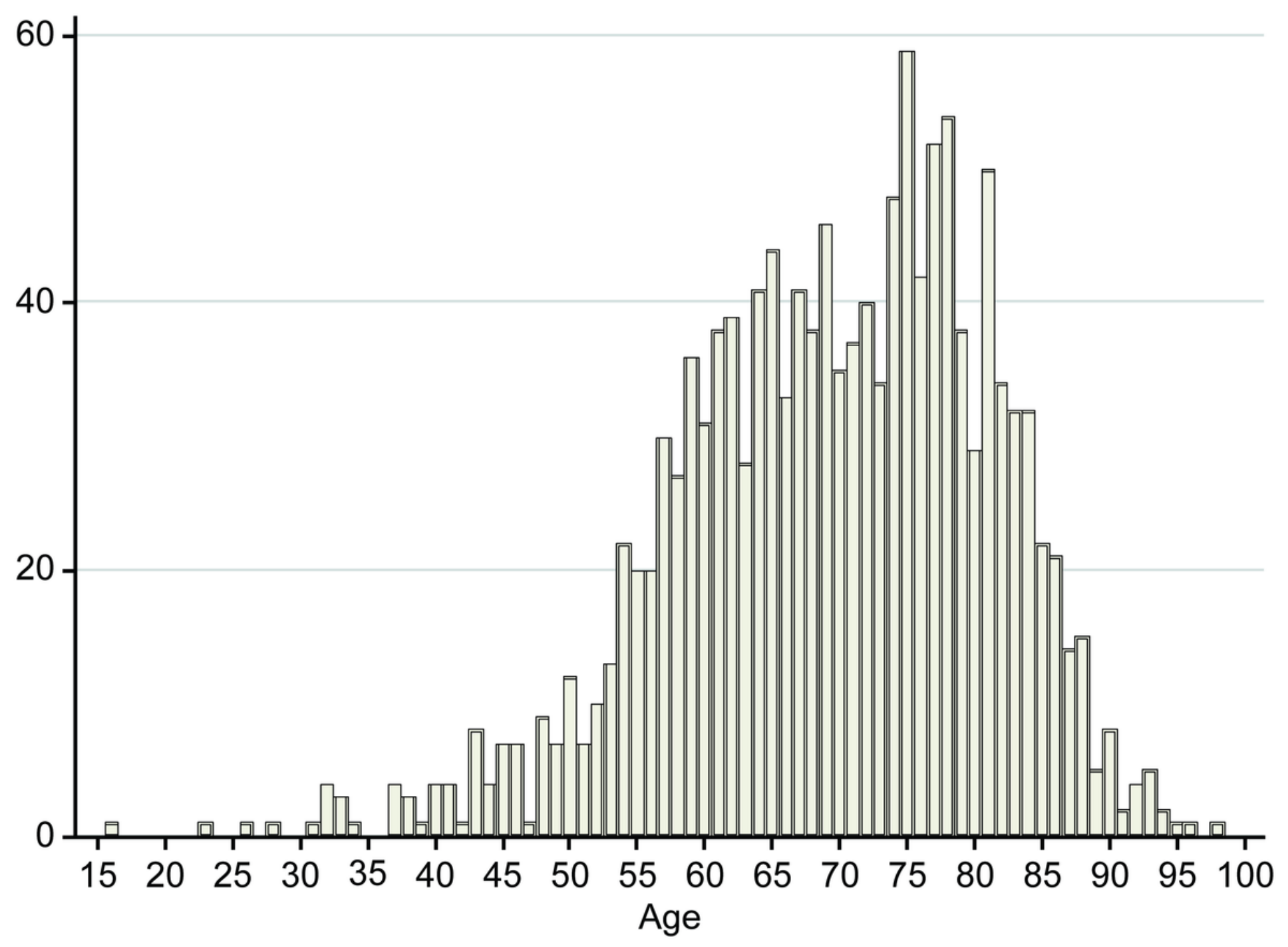

Figure 1

Age distribution histogram for 1366 patients diagnosed with stage IV gastric cancer 


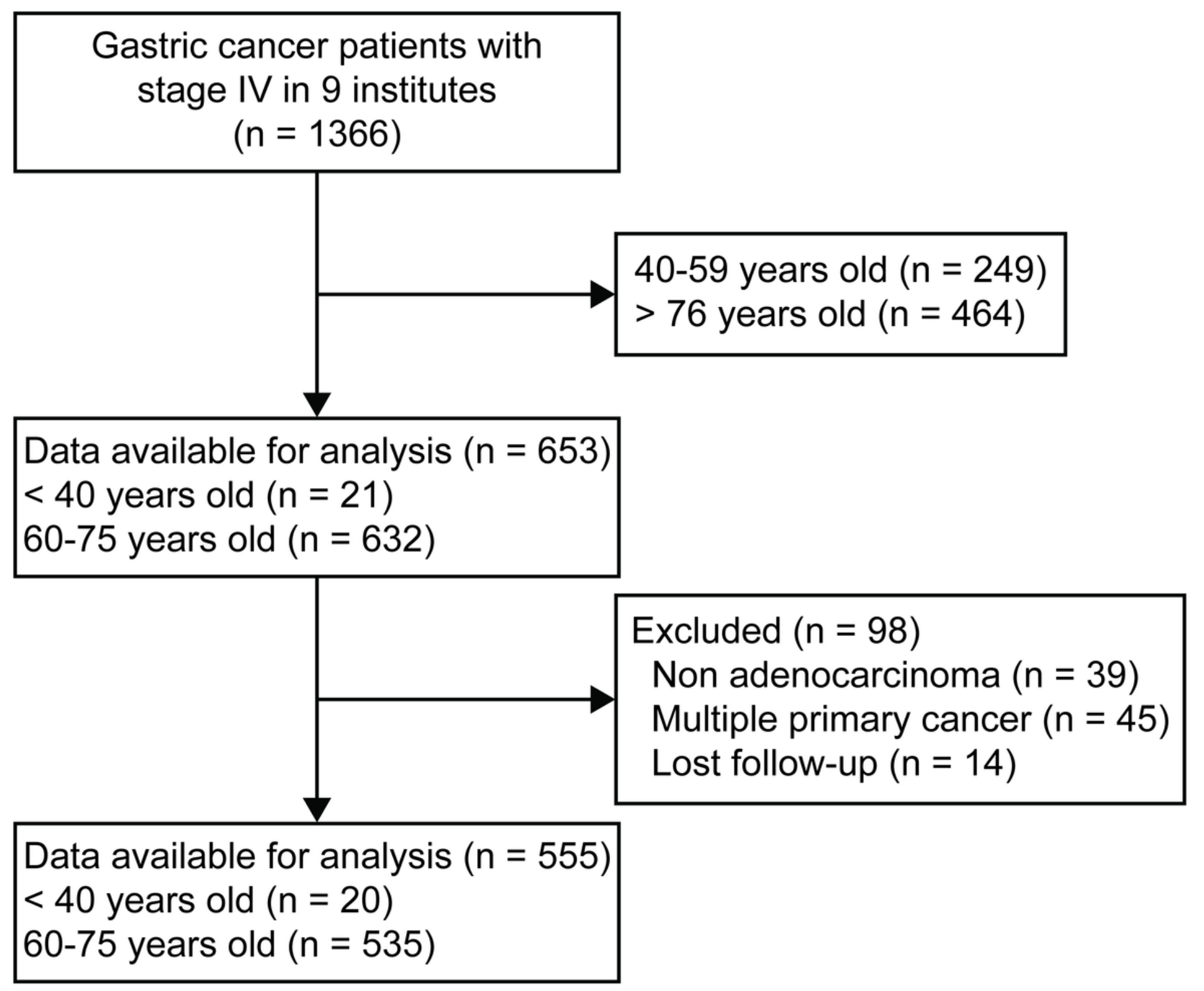

Figure 2

Patient enrollment flowchart. All 555 patients were selected from a population-based cohort of individuals with stage IV gastric cancer 


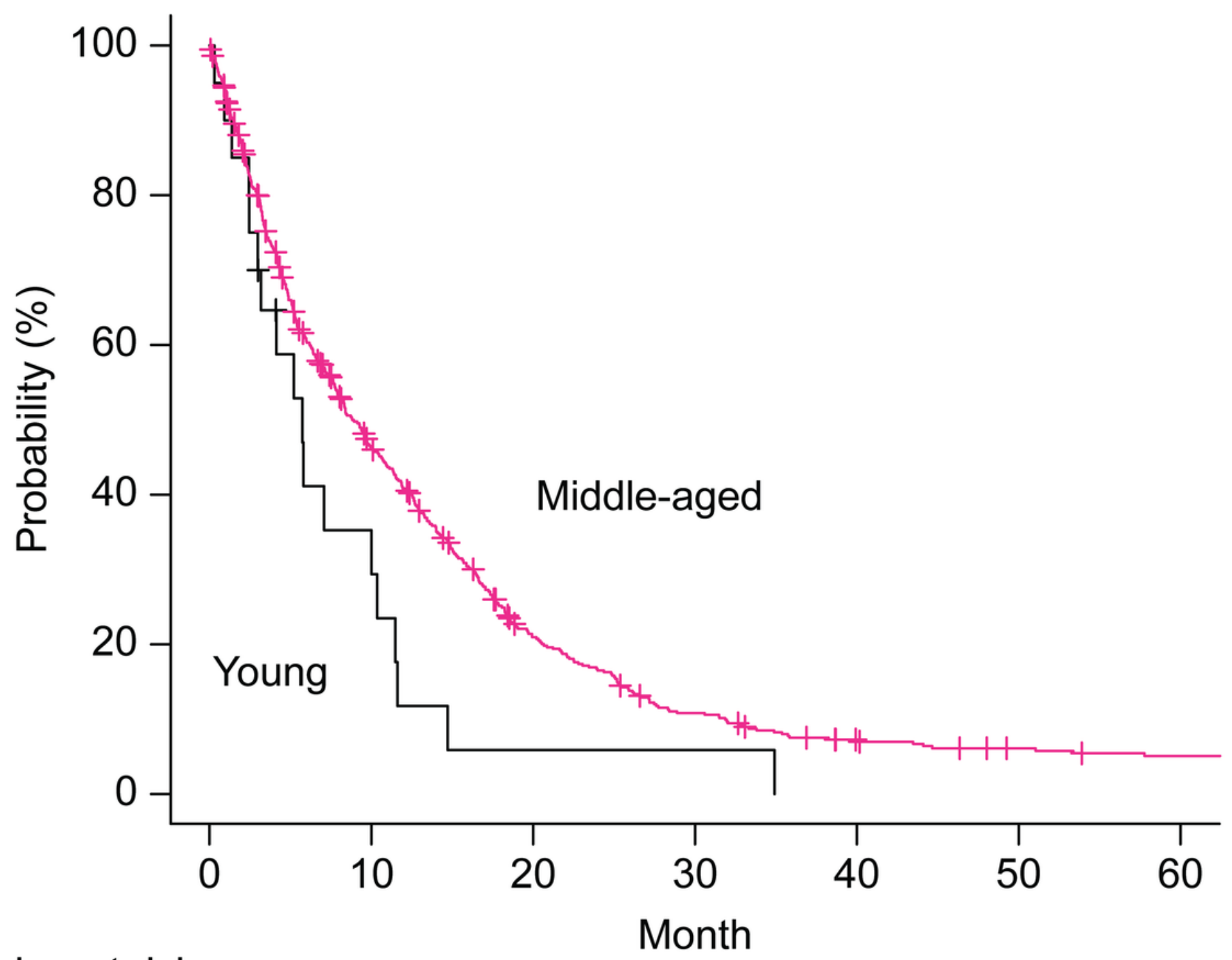

Number at risk

$\begin{array}{lccccccc}\text { Young } & 20 & 6 & 1 & 1 & 0 & 0 & 0 \\ \text { Middle-aged } & 535 & 228 & 94 & 47 & 25 & 18 & 14\end{array}$

Figure 3

Kaplan-Meier curves of overall survival 